\title{
Исследование возможности изготовления напряженных сверхрешеток InAs/GaSb методом газофазной эпитаксии из металлоорганических соединений
}

\author{
(C) Р.В. Левин ${ }^{1}$, В.Н. Неведомский ${ }^{1}$, Н.Л. Баженов ${ }^{1}$, Г.Г. Зегря ${ }^{1}$, \\ Б.В. Пушный ${ }^{1}$, М.Н. Мизеров ${ }^{2}$ \\ ${ }^{1}$ Физико-технический институт им. А.Ф. Иоффре Российской академии наук, \\ 194021 Санкт-Петербург, Россия \\ ${ }^{2}$ НТЦ микроэлектроники и субмикронных гетероструктур Российской академии наук, \\ 194021 Санкт-Петербург, Россия \\ E-mail: Lev@vpegroup.ioffe.ru
}

(Получена 3 июля 2018 г. Принята к печати 16 июля 2018 г.)

\begin{abstract}
Представлены первые результаты исследования возможности изготовления сверхрешеток на основе $\mathrm{InAs} / \mathrm{GaSb}$ методом газофазной эпитаксии из металлоорганических соединений. Экспериментально показана возможность изготовления гетероструктур с напряженной сверхрешеткой типа $\mathrm{InAs} / \mathrm{GaSb}$ с толщиной слоев 2-4нм. В спектрах электролюминесценции структур при $77 \mathrm{~K}$ наблюдается длинноволновый пик в районе 5 мкм $(0.25$ эВ), вероятно, связанный с напряженной сверхрешеткой, так как твердые растворы, которые могли бы образоваться на основе составных соединений, не обеспечивают полученную энергию рекомбинации носителей.
\end{abstract}

DOI: $10.21883 /$ FTP.2019.02.47112.8946

\section{1. Введение}

Постоянно идет поиск новых полупроводниковых материалов для создания источников излучения в ближнем и дальнем инфракрасном (ИК) диапазонах. При этом речь идет не о каскадных излучателях, а об излучателях с переходами зона-зона. До сих пор отсутствуют лазеры на длины волн $\lambda>4$ мкм, работающие при комнатной температуре. Главной причиной является безызлучательная оже-рекомбинация, которая снижает квантовую эффективность при высоких температурах.

В работе [1] впервые показано, что в гетероструктурах (ГС) II типа возможно подавление оже-рекомбинации. Поэтому наиболее перспективны, по нашему мнению, ГС со сверхрешетками II типа на основе материалов $\mathrm{A}^{\mathrm{III}} \mathrm{B}^{\mathrm{V}}$.

Впервые сверхрешетки (CP) на основе гетеропереходов II типа, в частности InAs/GaSb, для инфракрасных фотодетекторов предложили Смит и Мейлхиот в конце 1980-х годов [2]. С тех пор они широко используются в качестве как фотодетекторов, так и светоизлучающих приборов. В последнее время широко исследуются СР, выращенные методом газофазной эпитаксии из металлоорганических соединений (МОСГФЭ) [3] и молекулярно-лучевой эпитаксией (МЛЭ) [4]. Основным методом изготовления СР пока остается метод МЛЭ, но он не может быть предложен для массового производства. Метод МОСГФЭ широко используется для производства большого класса приборов оптоэлектроники (солнечные фотопреобразователи, лазеры, светодиоды и т.п.).

В данной работе представлены первые результаты исследования возможности изготовления СР на основе InAs/GaSb методом МОСГФЭ.

\section{2. Эксперимент и обсуждение}

Для определения возможных минимальных толщин слоев СР были изготовлены образцы, схематически представленные на рис. 1. Структуры состояли из подложки $n$-GaSb с концентрацией электронов $n=5-7 \cdot 10^{17} \mathrm{~cm}^{-3}$, буферного слоя $n-\mathrm{GaSb}:$ Те (толщина $d=0.5$ мкм, $\left.n=1 \cdot 10^{18} \mathrm{~cm}^{-3}\right)$, нелегированной СР $\mathrm{InAs} / \mathrm{GaSb}$, состоящей из 20 периодов (с запланированными одинаковыми толщинами слоев InAs и $\mathrm{GaSb} d<1$, 1 и 2 нм) и покрывающего слоя $p$-GaSb : $\mathrm{Si}(d=1$ мкм, концентрацией дырок $\left.p=1 \cdot 10^{18} \mathrm{~cm}^{-3}\right)$.

Bce эпитаксиальные образцы были выращены на установке МОСГФЭ AIX-200 (AIXTRON, Германия). Структуры выращивались на подложках $n$-GaSb (001). Давление в реакторе составляло 76 мм рт.ст. Подложка во время роста вращалась со скоростью 100 и более об/мин. Газ-носитель - очищенный водород с точкой росы не выше $-100^{\circ} \mathrm{C}$, а суммарный поток через реактор составлял 5.5 л/мин. Источниками элементов для роста были следующие соединения: триметилиндий (TMIn), триэтилгаллий (TEGa), триметилсурьма (TMSb) и арсин $\left(\mathrm{AsH}_{3}\right)$. В качестве источников легирующих примесей использовали диэтилтеллур (DETe), для доноров, и силан $\left(\mathrm{SiH}_{4}\right)$, для акцепторов, активная область не легировалась. Температура выращивания буферного и покрывающего слоев $\mathrm{GaSb}$ была $T=600^{\circ} \mathrm{C}$, a активной области $(\mathrm{CP})-T=500^{\circ} \mathrm{C}$. При росте буферного и покрывающего слоев $\mathrm{GaSb}$ соотношение элементов TMSb/TEGa составило 2, а сверхрешетки $\mathrm{AsH}_{3} / \mathrm{TMIn}=124$ и $\mathrm{TMSb} / \mathrm{TEGa}=22.5$. Скорость роста $V_{\mathrm{gr}}$ для буферного и покрывающего слоев $\mathrm{GaSb}$ составила $\sim 23$ нм/мин, для активной области $(\mathrm{CP}) \mathrm{GaSb}$ и $\mathrm{InAs} \sim 1.5 \mathrm{Hм} /$ мин (рис. 2 ). 
Для предотвращения роста на границах слоев материала переменного состава рост областей СР осуществлялся с прерыванием и продувкой реактора чистым водородом для полной смены газовой среды между ростом разных слоев. Время продувки $t$ реактора водородом определено по формуле $t \geq V / G$, где $V$ - объем реактора $\left(\right.$ в $\left.\mathrm{cm}^{3}\right), G$ - скорость протекания водорода $\left(\right.$ в $\left.\mathrm{cm}^{3} / \mathrm{c}\right)$, и для всех слоев время прерывания составляло $10 \mathrm{c}$. Выращивание каждого слоя $\mathrm{GaSb}$ начиналось с подачи

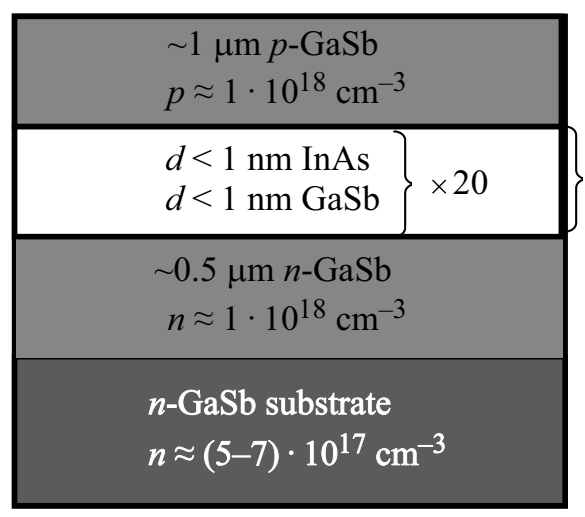

$a$

$\sim 25 \mathrm{~nm}$

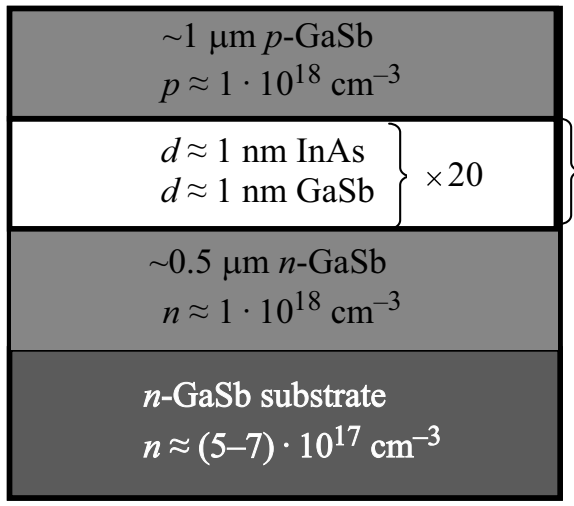

$b$

$\sim 40 \mathrm{~nm}$

L857

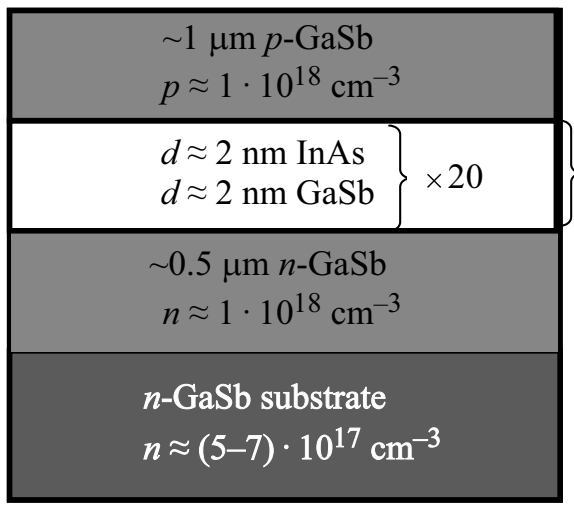

$c$

$\sim 80 \mathrm{~nm}$

L848

Рис. 1. Схематические изображения исследованных гетероструктур со сверхрешетками типа InAs/GaSb, состоящих из 20 периодов. Толщины нанослоев $\mathrm{GaSb}$ и $\mathrm{InAs} d$ в каждом образце сверхрешеток одинаковые: $a-$ образец L847, $d<1$; $b$ - образец L857, $d \approx 1 ; c$ - образец L848, $d \approx 2$.

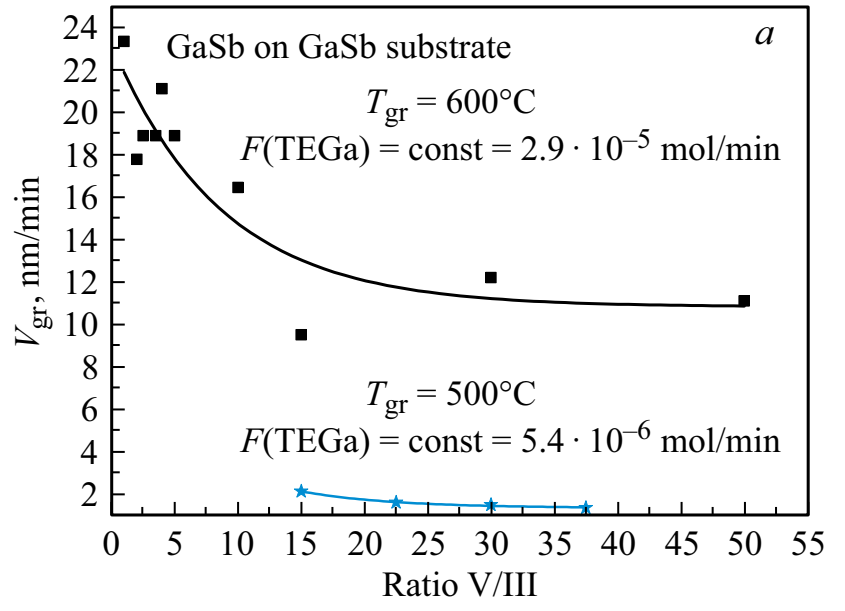

$$
\begin{aligned}
& \text { InAs on InAs substrate } \\
& \begin{array}{l}
T_{\mathrm{gr}}=600^{\circ} \mathrm{C} \\
F(\mathrm{TMIn})=\mathrm{const}=2.9 \cdot 10^{-5} \mathrm{~mol} / \mathrm{min}
\end{array} \\
&
\end{aligned}
$$

Рис. 2. Зависимости скоростей роста $V_{\text {gr }}$ эпитаксиальных слоев $\mathrm{GaSb}(a)$ и InAs $(b)$ от соотношения молярных потоков элементов V и III групп.

TEGa на 2 c раньше TMSb, а рост каждого слоя InAs с подачи $\mathrm{AsH}_{3}$ на 2 c раньше TMIn для предотвращения возможности роста InSb, что было предсказано в работе [5]. Особенности выращивания слоев СР описаны в патенте РФ [6].

Толщины слоев в СР определялись временем роста в соответствии с зависимостями на рис. 2.

Исследования микроструктуры образцов выполнялись методом просвечивающей электронной микроскопии на микроскопе JEM2100F с ускоряющим напряжением 200 кВ. Образцы для электронной микроскопии были подготовлены в поперечном сечении по общепринятой процедуре с использованием механического шлифования-полирования и финишного распыления ионами $\mathrm{Ar}^{+}$с энергией $3-3.3$ кэВ под скользящим углом к поверхности. При исследовании в электронном микроскопе применялся режим дифракционного контраста в двулучевых условиях.

В результате исследований установлено, что образец L847 (рис. 1, $a$ ) имеет очень большую плотность протяженных дефектов $\left(>5 \cdot 10^{11} \mathrm{~cm}^{-2}\right)$ в области СР 
(рис. 3, $a$ ). Плотность дефектов $(1-2) \cdot 10^{10} \mathrm{~cm}^{-2}$ в образце L857 (рис. $1, b$ ) была существенно ниже (рис. $3, b$ ), чем в образце L847. B образце L848 (рис. 1,c) дефектов довольно мало $\left(<4 \cdot 10^{9} \mathrm{~cm}^{-2}\right)$ (рис. $\left.3, c\right)$.

Толщина слоев неоднородна, как в латеральном направлении, так и от слоя к слою, а границы имеют более темный контраст, чем GaSb и InAs. Это говорит об образовании на границах тонких переходных слоев $\mathrm{InGaSb}$ и (или) GaAsSb.

B образце L847 не найти участка, не содержащего структурных дефектов, о толщинах слоев говорить очень сложно. В образце L848 структурные дефекты не наблюдаются, но толщины слоев меняются как в латеральном направлении, так и от слоя к слою. Толщины слоев составили 1.2-3.2 при заданных 2 нм. В образце L857 структурные дефекты появляются лишь в верхней части образца

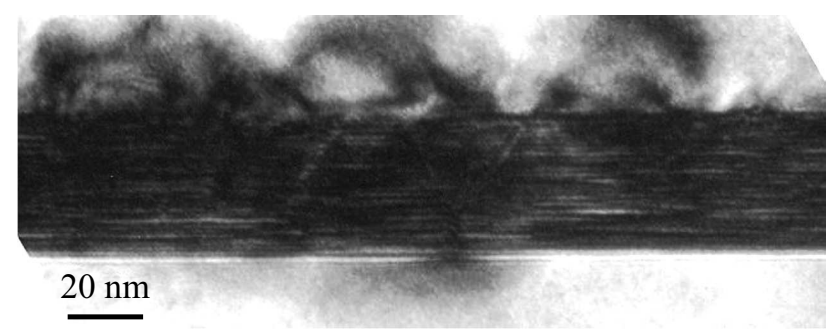

L847

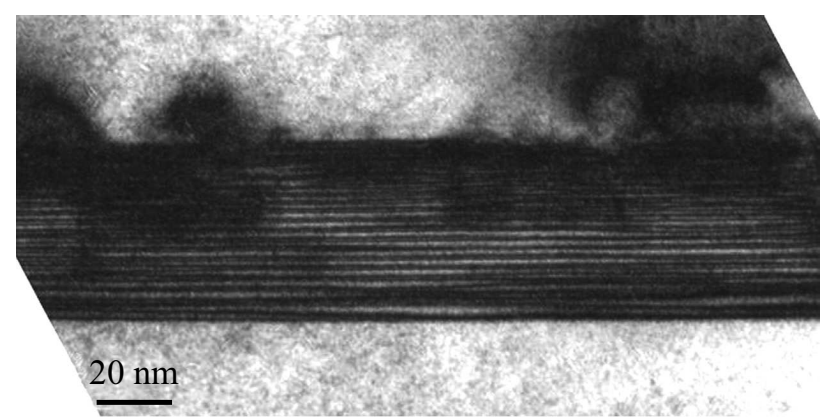

L857

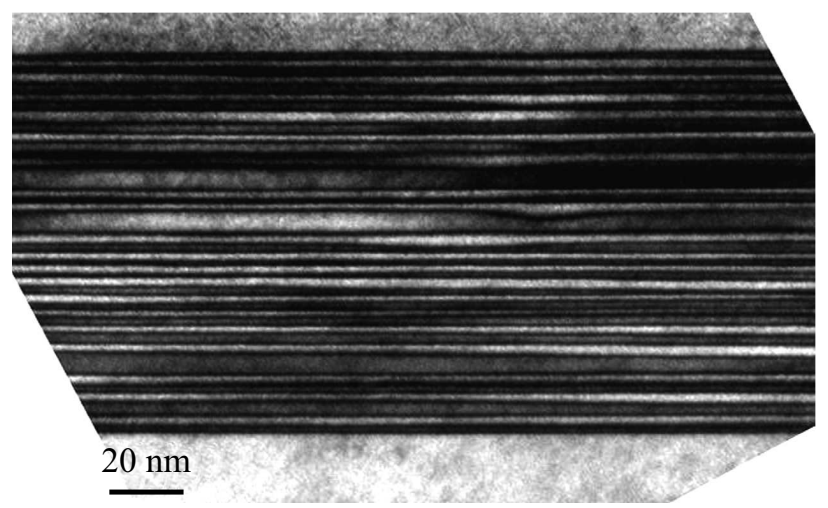

L848

Рис. 3. Темнопольные изображения поперечного сечения (11̄0) образцов, сделанные в отражении с $g=(002)$, чувствительном к изменениям химического состава: L847, $d<1$; L857, $d \approx 1 ; \mathrm{L} 848, d \approx 2$.

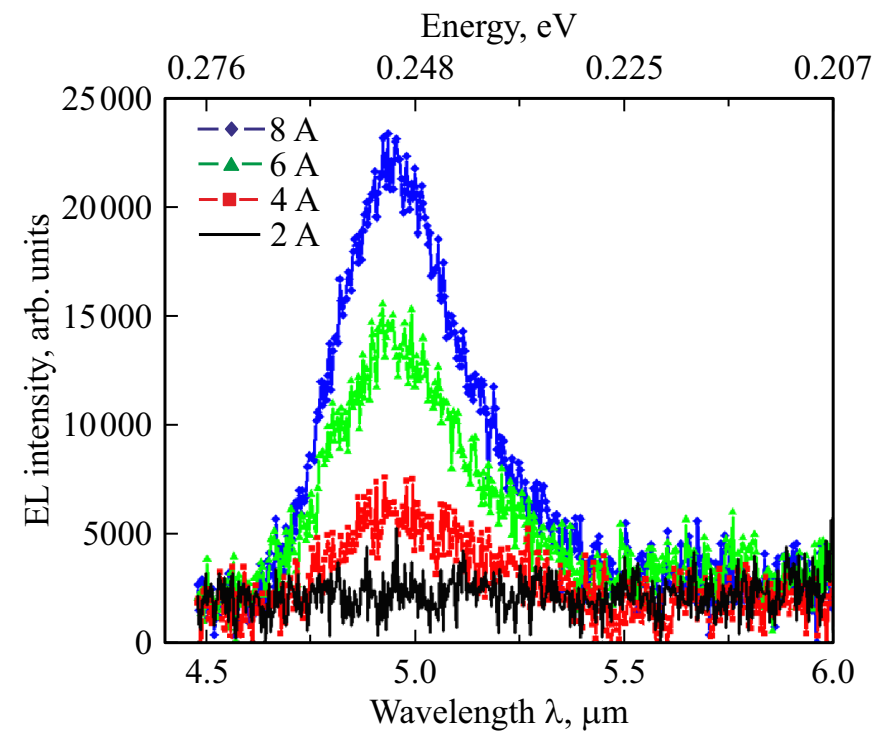

Рис. 4. Спектры электролюминесценции (EL) образца L848 при $77 \mathrm{~K}$ и различных токах возбуждения.

Можно предположить, что в образце L847 вместо СР образовался сплошной слой твердого раствора с ориентировочным составом $\mathrm{Ga}_{0.5} \mathrm{In}_{0.5} \mathrm{As}_{0.4} \mathrm{Sb}_{0.6}$.

На основе структуры (образец L848) были изготовлены светодиоды диаметром $\sim 700$ мкм. Спектры электролюминесценции (ЭЛ) изучались в диапазоне температур $70<T<300 \mathrm{~K}$ при возбуждении импульсами тока длительностью 1 мкс с частотой 1 кГц.

Спектры ЭЛ при $T=77 \mathrm{~K}$ показаны на рис. 4 . Ток возбуждения в импульсе был в диапазоне 2-8А. В спектре наблюдался явный максимум, соответствующий энергии 0.25 эВ (5.0 мкм). Положение максимума в спектре излучения отличается от энергии запрещенной зоны материалов CP InAs, GaSb и возможного твердого раствора $\mathrm{Ga}_{0.5} \mathrm{In}_{0.5} \mathrm{As}_{0.4} \mathrm{Sb}_{0.6}$, и это можно объяснить наличием напряженной СР.

\section{3. Заключение}

В результате проведенных исследований экспериментально показана возможность изготовления гетероструктур с напряженной сверхрешеткой типа InAs/ $\mathrm{GaSb}$ с толщиной слоев $2-4$ нм методом МОСГФЭ. Исследования будут продолжены с целью изготовления сверхрешеток с толщинами слоев $<4$ нм и с минимальной толщиной переходных областей на границах слоев.

Авторы выражают благодарность П.Н. Брункову за полезные обсуждения, К.Д. Мынбаеву, А.С. Усиковой и Н.Д. Ильинской за помощь в изготовлении образцов и измерениях.

Работа выполнена при частичной поддержке гранта РФФИ № 16-08-01130-а. 
Работа по выращиванию сверхрешеток выполнялась на оборудовании ЦКП „Элементная база радиофотоники и наноэлектроники“ при НТЦ микроэлектроники РАН.

Исследования методом просвечивающего электронного микроскопа выполнены с использованием оборудования федерального ЦКП „Материаловедение и диагностика в передовых технологиях“, поддержанного Министерством образования и науки России (идентификатор проекта RFMEFI62117X0018).

\title{
Список литературы
}

[1] G.G. Zegrya, A.D. Andreev. Appl. Phys. Lett., 67 (12), 2681 (1995).

[2] D.L. Smith, C. Mailhiot. J. Appl. Phys., 62 (6), 2545 (1987).

[3] Y. Huang, J.-H. Ryou, R.D. Dupuis, D. Zuo, B. Kesler, S.-L. Chuang, H. Hu, K.-H. Kim, Y.T. Lu, K.C. Hsieh, J.-M. Zuo. Appl. Phys. Lett., 99, 011109 (2011).

[4] R. Taalat, J.-B. Rodriguez, M. Delmas, Ph. Christol. J. Phys. D: Appl. Phys., 47, 015101 (2014).

[5] Р.В. Левин, А.А. Усикова, В.Н. Неведомский, Н.Л. Баженов, К.Д. Мынбаев, Б.В. Пушный, Г.Г. Зегря. Тез. докл. XXV Межсдунар. науч.-техн. конф. по фотоэлектронике и приборам ночного видения (М., 2018) т. 1, с. 247.

[6] В.М. Андреев, Р.В. Левин, Б.В. Пушный. Патент РФ № 2611692 от 28.02.2017.

Редактор Л.В. Шаронова

\section{Study of the possibility of manufacturing strained superlattices $\operatorname{InAs} / \mathrm{GaSb}$ by MOCVD metod}

\author{
R.V. Levin ${ }^{1}$, V.N. Nevedomskyi ${ }^{1}$, N.L. Bazhenov', \\ G.G. Zegrya' ${ }^{1}$, B.V. Pyshnyi ${ }^{1}$, M.N. Mizerov ${ }^{2}$ \\ ${ }^{1}$ loffe Institute, \\ 194021 St. Petersburg, Russia \\ 2 Submicron Heterostructures for Microeletctonics \\ Research and Engineering Center, \\ Russuan Academy of Sciences, \\ 194021 St. Petersburg, Russia
}

\footnotetext{
Abstract The paper presents the first results showing the possibilities of manufacturing InAs/GaSb based superlattices by metalloorganic chemical phase deposition (MOCVD). The possibility of manufacturing heterostructures with a stressed superlattice of InAs/GaSb type with a layer thickness of $2-4 \mathrm{~nm}$ is experimentally shown. In the electroluminescence spectra at $77 \mathrm{~K}$ of the structures, a long-wave peak is observed in the region of $5.0 \mu \mathrm{m}$ $(0.25 \mathrm{eV})$, probably associated with a stressed superlattice because solid solutions, which could be formed on the basis of composite compounds, do not provide the recombination energy of the carriers.
} 